\title{
Cloning, Biochemical Characterization and Inhibition of Alanine racemase from Streptococcus iniae
}

Murtala Muhammad, Yangyang Li, Siyu Gong, Yanmin Shi, Jiansong Ju, Baohua

$$
\text { Zhao*, Dong Liu* }
$$

College of Life Science, Hebei Normal University, Shijiazhuang 050024, China;

*Correspondence: Baohua Zhao and Dong Liu; E-mail: Baohua519@126.com, pqw1234@163.com; College of Life Science, Hebei Normal University, Shijiazhuang 050024, China.

Running Title: Inhibitors of alanine racemase

Summary statement: Antimicrobial target 


\section{ABSTRACT}

Streptococcus iniae is a pathogenic and zoonotic bacteria that impacted high mortality to many fish species, as well as capable of causing serious disease to humans. Alanine racemase (Alr, EC 5.1.1.1) is a pyridoxal-5'-phosphate (PLP)-containing homodimeric enzyme that catalyzes the racemization of L-alanine and D-alanine. In this study, we purified alanine racemase from the pathogenic strain of $S$. iniae, determined its biochemical characteristics and inhibitors. The alr gene has an open reading frame (ORF) of $1107 \mathrm{bp}$, encoding a protein of 369 amino acids, which has a molecular mass of $40 \mathrm{kDa}$. The optimal enzyme activity occurred at $35^{\circ} \mathrm{C}$ and a $\mathrm{pH}$ of 9.5. The enzyme belongs to the PLP dependent enzymes family and is highly specific to L-alanine. S.iniae Alr can be inhibited by some metal ions, hydroxylamine and dithiothreitol (DTT). The kinetic parameters $K_{m}$ and $V_{\max }$ of the enzyme were $33.11 \mathrm{mM}, 2426$ units/mg for L-alanine and $14.36 \mathrm{mM}, 963.6$ units/mg for D-alanine. Finally, the $50 \%$ inhibitory concentrations $\left(\mathrm{IC}_{50}\right)$ values and antibiotic activity of two alanine racemase inhibitors, were determined and found to be effective against both gram positive and gram negative bacteria employed in this study. The important role of alanine racemase as a target of developing new antibiotics against $S$. iniae highlighted the usefulness of the enzyme for new antibiotics discovery.

Keywords: Streptococcus iniae; Alanine racemase; Peptidoglycan; Homogentisic acid and Hydroquinone. 


\section{Introduction}

Streptococcus iniae (S. iniae) is a gram-positive and most commonly reported fish streptococcal pathogen responsible for high economic loses of aquaculture industries around the world. The zoonotic bacteria was also reported to cause bacteremia, cellulitis, meningitis, and osteomyelitis in human (Guo et al., 2018; Tavares et al., 2018). Vaccines and antibiotics were currently employed for minimizing the impact of the disease, however, recent studies revealed that the bacteria has so far developed resistance against many potential antibiotics (Tavares et al., 2018; Muhammad et al., 2019) as such, additional efforts for developing more effective vaccines and antibiotics are necessary steps for circumventing the threat of its infection (Saavedra et al., 2004). One promising target of new antibiotics discovery is alanine racemase.

Alanine racemase (Alr; E.C. 5.1.1.1) is an enzyme that catalyzes the interconversion of 1- alanine and D-alanine using a pyridoxal 5-phosphate (PLP) as a cofactor (Tassoni et al., 2017). d-alanine was used for the synthesis of peptidoglycan of the bacterial cell wall. it is directly involved in cross-linking of adjacent peptidoglycan strands and also present in lipoteichoic acids of Gram-positive bacteria (Liu et al., 2018; Ray et al., 2018). There are two isoforms (non-homologous) of alanine racemase genes (alr and dadX). The alr gene which is constitutively expressed is an essential enzyme for cell wall synthesis while the expression of $d a d X$ is induced in the presence of high concentrations of L- or D-alanine. DadX is basically required for 1-alanine catabolism, forming a substrate for d-alanine dehydrogenase (dadA) (Duque et al., 2017). The bacterial cell wall is indispensable for the survival and viability of bacteria (Liu et al., 2019) and has always been an interesting target for many antibiotics and antimicrobial agents (Anthony et al., 2011). Alanine racemase is ubiquitous among bacteria and rare in eukaryotes but absent in humans (Kawakami et al., 2018), hence it emerges as an attractive and potential therapeutic target for the antimicrobial drug (Wang et al., 2017).

Numerous inhibitors were identified as able to affect the activity of alanine racemase (Kim et al., 2003a; Kim et al., 2003b). Many of the inhibitors were structural analogs of alanine: they interact with the enzyme-bound PLP, covalently bound to some eukaryotic PLP-dependent enzymes and lead to cellular toxicity (Toney, 2005). PLP-related off-target 
effects could be overcome by using enzyme inhibitors that are not substrate analogs. Structure-based approach and molecular modeling have been employed to discover novel alanine racemase inhibitors which are devoid of affinity for the PLP and hence off-target effects (Lee et al., 2013; Azam and Jayaram, 2018).

In this study, we identified and purified the alanine racemase from $S$. iniae HNM-1 strain that was previously isolated from an infected Chinese sturgeon (Acipenser sinensis) after massive mortality as a result of its infection (Muhammad et al.,2019). We characterized its enzymatic properties, substrate specificity and kinetic parameters. We also explore the potentiality of the enzyme as an attractive antimicrobial target against $S$. iniae. We determined the $50 \%$ inhibition concentrations $\left(\mathrm{IC}_{50}\right)$ of two alanine racemase inhibitors and their antimicrobial susceptibility against six opportunistic pathogens including S. iniae, in quest of providing the possible solutions against antibiotics resistance and bacterial infections.

\section{Results}

\subsection{Identification of $S$. iniae alanine racemase gene}

According to the genomic sequence of $S$. iniae, the bacteria have a single putative alanine racemase $(a l r)$ gene. The alr gene has an open reading frame of $1107 \mathrm{bp}$ that encodes a 369 amino acids protein (SiAlr) with a molecular mass of $39.82 \mathrm{kDa}$. The nucleotide sequence of alr has been submitted to GenBank under accession number MK620909.

The deduced amino acid sequence has 76\%, 67\%, 63\% and 47\% similarities with alanine racemase of Streptococcus pyogenes, Streptococcus agalactiae, Streptococcus pneumoniae, and Enterococcus faecalis, respectively. Phylogenetic analysis of alanine racemase from different bacteria revealed an evolutionary relationship among them. The phylogenetic tree consists of two distinct clades. The enzyme is clustered with other Streptococci species, such as $S$. pyogenes, S. agalactiae, S. pneumoniae and E. faecalis. These sequences, from gram-positive bacteria, were classified into one group. The sequences from gram-negative bacteria, such as Pseudomonas aeruginosa, Aeromonas hydrophila and Corynebacterium glutamicum were classified into another (Fig. 1). The evidence indicated that these alanine racemases evolved independently from a common ancestor and formed two isolated genes.

Multiple sequence alignment of SiAlr with sequences of other 10 species suggested that some regions are absolutely conserved in SiAlr, which includes PLP binding motif near the 
N-terminus (AVVKANAYGHG) and the two catalytic amino acid residues of the active center (Lys 40 and Tyr 274). The eight residues making up the entryway to the active site (inner layer: Ala 174, Tyr 273, Tyr 282 and Tyr 366; middle layer: Asp 166, Arg 298, Arg 318 and Ile 364) (Fig. 2).

\subsection{Expression and Purification of SiAlr}

The SiAlr protein was expressed in E.coli (DE3) incubated overnight at $16{ }^{\circ} \mathrm{C}$. The was purified to homogeneity using Ni-agarose affinity chromatography. The protein has a relative molecular mass of $39.82 \mathrm{kDa}$ as estimated by SDS-PAGE, which was similar to the calculated molecular mass. Calculated relative molecular mass and western blotting analysis using the anti-poly-His antibody confirmed that $39.82 \mathrm{kDa}$ protein is SiAlr (Fig 3).

\subsection{Characterization of the enzyme}

The optimal temperature of SiAlr was approximately $35^{\circ} \mathrm{C}$. The enzyme was found to be very stable at the temperature of 30 and $35^{\circ} \mathrm{C}$, with more than $50 \%$ residual activity. The optimal $\mathrm{pH}$ of SiAlr was approximately 9.5 at $35^{\circ} \mathrm{C}$. The enzyme was found to be very stable with more than $50 \%$ residual activity after incubation for 2 hours at a pH of 8.5 to 9.5 (Fig 4). Thus demonstrating that SiAlr is a basophilic enzyme.

Various chemicals and metal ions were reported to inhibit the activity of alanine racemases. The results revealed that the enzyme activity was inhibited by most of the metal ions, but markedly inhibited by $\mathrm{Ni}^{2+}, \mathrm{Co}^{2+} \mathrm{Zn}^{2+}$ and $\mathrm{Fe}^{2+}$ (Fig 5).

\subsection{Effect of reducing agents on the activity of SiAlr}

Many inhibitors of alanine racemase have been discovered (Wang et al., 2017). The enzyme almost completely lost its activity after treatment with 1 and $10 \mathrm{mM}$ hydroxylamine. Addition of $0.1 \mathrm{mM}$ hydroxylamine reduced the activity of the enzyme by $80 \%$. Treatment of SiAlr with $1 \mathrm{mM} / \mathrm{L}$ of DTT resulted in a 70\% loss of its activity and completely inhibited at the concentration of $3 \mathrm{mM}$ (Table 2).

We examined the role of PLP in the activity of SiAlr by resolving the enzyme to Apo-enzyme by Hydroxylamine treatment. The Apo-enzyme almost completely lost its activity after treatment with $10 \mathrm{mM}$ hydroxylamine. Addition of 0.01, 0.04 and 0.06mM PLP make the enzyme regained up to $56 \%, 83 \%$ and $96 \%$ of its activity, respectively. The result 
indicated that SiAlr is a PLP-dependent enzyme that requiring more than 0.01 mM PLP to maintain its activity (Table 2).

\subsection{Substrate specificity}

Alanine racemase is a highly conserved bacterial enzyme and known to be very specific to its substrate (Patrick et al., 2002). As shown in Fig 6, the enzyme was highly specific to L-alanine and showed week activity with L-phenylalanine (11\%), L-Histidine (20\%), and L-Asparagine (10\%). This result indicates that SiAlr has strict substrate specificity.

\subsection{Kinetic parameters determination}

Kinetic parameters of SiAlr were determined using HPLC. The substrate affinity constant $\left(K_{m}\right)$ for L-alanine was $33.11 \mathrm{mM}$ with a maximal velocity $\left(V_{\max }\right)$ of 2,426 units/mg, while the D-alanine $K_{m}$ value was $14.36 \mathrm{mM}$ with a $V_{\max }$ of 963.6 units/mg. The $V_{\max }$ of L-alanine was more than twice than that of its enantiomer. These indicated that the enzyme has a greater binding affinity for L- alanine than for D- alanine, and the conversion of L- to D-alanine was more rapid than the reverse conversion. The equilibrium constant $\left(K_{e q}(\mathrm{~L} / \mathrm{D})\right)$ was 1.09 , which is consistent with the reported theoretical equilibrium constant $\left(K_{e q}=1\right)$ for alanine racemase (Liu et al., 2015) (Table 3).

\section{7. $\mathrm{IC}_{50}$ determination}

In our previous study, we found that homogentisic acid and hydroquinone are two alanine racemase inhibitors with minimal cytotoxicity against mammalian cells and can be utilized as potential agents of antibiotics (Wang et al., 2017). In this study we investigated the inhibitory effects of homogentisic acid and hydroquinone on SiAlr, DMSO was used as the blank control and DCS, a known alanine racemase inhibitor, as the positive control. The results showed that the $\mathrm{IC}_{50}$ values of hydroquinone and homogentisic acid were $11.39 \mu \mathrm{M}$ and $12.27 \mu \mathrm{M}$. The $\mathrm{IC}_{50}$ values of hydroquinone and homogentisic acid were 3 and 3.3 times higher than that of DCS (Fig 7).

\subsection{Antimicrobial activity of alanine racemase inhibitors}

The minimum inhibitory concentration (MIC) was conducted to determine the antimicrobial activity of two alanine racemase inhibitors against $S$. iniae HNM-1 and several conditional pathogenic bacteria. The results showed that hydroquinone and homogentisic acid have broad-spectrum antibiotic activities against both gram-positive and gram-negative bacteria. Hydroquinone showed good antibiotic activity against $S$. iniae HNM-1 
with MIC value of $25 \mu \mathrm{g} / \mathrm{ml}$, however, showed moderate antibiotic activity against other strains with MIC value of 130-210 $\mu \mathrm{g} / \mathrm{ml}$. Homogentisic acid demonstrated moderate antibiotic activity against bacteria tested with MIC value of $180-250 \mu \mathrm{g} / \mathrm{ml}$. Interesting, hydroquinone and homogentisic acid had no antibiotic activity against Pseudomonas aeruginosa.

\section{Discussion}

S. iniae is a gram-positive and one of the leading fish pathogens responsible for causing morbidity and mortality of more than 30 fish species (Aruety et al., 2016). S. iniae HNM-1 strain was isolated from an infected Chinese sturgeon (Acipenser Sinensis) after a disease outbreak that causes high morbidity and mortality (Muhammad et al., 2019). The classification of $S$. iniae HNM-1 was confirmed by molecular analysis of $16 s$ rRNA gene sequence. The sequence was deposited at the NCBI Genbank database under accession number KY781829. According to the genomic sequence of $S$. iniae 89353 strain (NCBI accession number CP017952.1), the bacteria have a single putative alanine racemase (alr) gene. As reported earlier, most of the Gram-positive bacteria, including Lactobacillus plantarum (Palumbo et al., 2004), Bacillus anthracis (Couñago et al., 2009), Mycobacterium tuberculosis (Nakatani et al., 2017) and Mycobacterium smegmatis (Chacon et al., 2002), appear to possess only one alanine racemase gene.

The optimal $\mathrm{pH}$ and temperature of SiAlr were 9.5 and $35^{\circ} \mathrm{C}$ respectively, which were similar to alanine racemase from Aeromonas hydrophila (Liu et al., 2015) and Bacillus pseudofirmus OF4 (Ju et al., 2009). Nearly all characterized alanine racemases have optimal $\mathrm{pH}$ more than 8 including enzymes from acidophile, Acidiphilium organovorum and Acetobacter aceti (Seow et al., 1998; Francois and Kappock, 2007). SiAlr is a mesophilic enzyme, stable at a temperature of $0^{\circ} \mathrm{C}$ to $40^{\circ} \mathrm{C}$. Thermal stability of an enzyme is correlated with the host bacteria physiology and environment, thermophilic bacteria Alr are more stable than mesophilic and psychrotroph bacteria (Soda and Tanizawa, 1990; Yokoigawa et al., 1993). The effects of metal ions and other reagents on enzymes are diverse. Studies of alanine racemase from $A$. hydrophila have revealed that divalent cations, such as $\mathrm{Ca}^{2+}$ and $\mathrm{Mg}^{2+}$ enhanced racemization of alanine racemase (Liu et al., 2015). SiAlr was characterized as 
PLP-dependent racemase and showed high substrate specificity to alanine which is similar to most of the characterized Alanine racemases (Kawakami et al., 2018).

Many studies have focused on alanine racemase to develop antibacterial drugs for multiple bacterial species (Scaletti et al., 2012; Shrestha et al., 2017). Unlike D-cycloserine which is a cyclic analog of alanine and exerted its inhibitory effect through interaction with the enzymebound PLP cofactor (Batson et al., 2017), both homogentisic acid and hydroquinone are not structural analogs of Alr as such they are not interfering with other PLP dependent enzymes (Wang et al., 2017). According to the results of antimicrobial activity assay, the two inhibitors are capable of inhibiting both gram-positive and gram-negative bacteria with varying efficacies except Pseudomonas aeruginosa. The reason for two compounds showed no antimicrobial activity against $P$. aeruginosa may be that homogentisic acid is a normal product of $P$. aeruginosa and $P$. aeruginosa contained hydroquinone oxidase that oxidized hydroquinone (Higashi, 1958; Hunter and Newman, 2010).

Several alanine racemases have been identified and characterized form the Streptococcus species. Alanine racemase from Streptococcus faecalis NCIB 6459 with the molecular weight of $42 \mathrm{kDa}$ was the first one that was purified and characterized (Badet and Walsh, 1985). Strych et al isolated and characterized the alanine racemase gene from Streptococcus pneumoniae. They obtained preliminary crystals of S. pneumoniae Alr, and intend to incorporate the enzyme into the structural-based drug design program (Strych et al., 2007). Im et al solved the structure of S. pneumoniae Alr and identified three regions on the enzyme that could be targeted for structure-based drug design (Im et al., 2011). Qiu et al. first provided the first evidence that D-Ala metabolism is essential for planktonic growth and biofilm formation of Streptococcus mutans. It would be possible to take Alr of S. mutans as an antibacterial target to screen and optimize the safety and effective specificity of agents (Qiu et al., 2016). Wei Y. et al. confirmed that alr is an essential factor to maintain the growth and cell wall integrity of $S$. mutans (Wei et al., 2016). A serial of in vivo and in vitro experiments demonstrate that Alr is essential for the cariogenicity of $S$. mutans. Alr might represent a promising drug target to control the prevalence of cariogenic $S$. mutans in a multi-species microbial consortium and be a potential target for the prevention and treatment of caries (Liu et al., 2018). Therefore, Alr is regarded as a drug target for further investigation to develop effective drugs against $S$. iniae and a subject of mutational studies for the development of mutants with enhance activity that can be utilized for industrial purposed, since d-alanine is also widely used for the production of 
infusion solutions (Nachbauer et al., 1984), food additive (Awasthy et al., 2012), and in the manufacturing of artificial fibers (Teulé et al., 2009).

\subsection{Conclusion}

Purification and characterization of Alr from both gram-positive and gram-negative bacteria is an essential step towards an in-depth understanding of enzyme divers features, design new broad-spectrum antibiotics and used for site-directed mutagenesis in order to improve the enzyme catalysis and stability. Hydroquinone and homogentisic acid are promising inhibitors of Alr that are capable of inhibiting the growth of both gram-positive and gram-negative bacteria. Future investigation will focus on finding the physiological role of Alr, exploring new novel antimicrobial agents against $S$. iniae and improving their efficacy by designing and analyzing their new derivatives that may have improved antimicrobial activity.

\section{Materials and Methods}

\subsection{Strains, plasmids, and growth conditions}

The characters of bacterial strains and plasmids used in this context were summarized in Table 1. S. iniae HNM-1 was cultured at $35^{\circ} \mathrm{C}$ in Tryptone soy yeast extract (TSYE) medium. Escherichia coli (E. coli) DH5a, E. coli BL21 strains, Salmonella, Staphylococcus aureus, Acinetobacter baumannii and Pseudomonas aeruginosa were cultured in Luria Bertani (LB) media at $37^{\circ} \mathrm{C}$ or $35^{\circ} \mathrm{C}$. For the final concentration of antibiotic, $100-\mathrm{g} / \mathrm{mL}$ ampicillin (Amp) was used in this study.

\subsection{Cloning of alanine racemase gene}

Primers were design based on the alr gene sequence of $S$. iniae 89353 strain (NCBI accession number CP017952.1). The genomic DNA of S. iniae HNM-1was extracted and amplified using the primers: Alr-F-( 5'-GCACCATGGATGATTTCAAGTTTG-3') and Alr-R- (5'-TCACTCGAGATCCCGATAAAGC-3'), with NcoI and XhoI restriction sites, underlined respectively. PCR product was cloned in pMD19-T cloning vector to construct pMDalr and transformed to E. coli DH5 $\alpha$. The alr gene was digested with restriction endonucleases and cloned into expression vector pET-22b (+), forming recombinant plasmid pET22b-alr, and subsequently, the gene was sequenced and analyzed. The deduced amino 
acid sequence of the ORF was analyzed by the Blast software. Multiple amino acid sequence alignment and phylogenetic relationships among alanine racemase of $S$. iniae HNM-1 (SiAlr) and other bacteria were constructed with Clustal Omega.

\subsection{Expression and purification of alanine racemase}

The expression vector was transformed into E.coli BL21 (DE3) for protein expression, a single colony of the transformed E.coli was inoculated in $100 \mathrm{ml}$ LB medium which contained ampicillin $(100 \mu \mathrm{g} / \mathrm{ml})$ and incubated at $35^{\circ} \mathrm{C}$. Protein expression was induced when the $\mathrm{OD}_{600}$ reaches 0.6 by addition of IPTG at a final concentration of $1 \mathrm{mM}$, and re-incubated overnight at $16^{\circ} \mathrm{C}$ or at $35^{\circ} \mathrm{C}$ for 5 hours. Cells were collected and resuspended in $20 \mathrm{ml}$ binding buffer (50 $\mathrm{mM} \mathrm{NaH}_{2} \mathrm{PO}_{4}, \mathrm{pH} 8.0,300 \mathrm{mM} \mathrm{NaCl}$ and $10 \mathrm{mM}$ imidazole), lysed on ice by sonication for 40 minutes, and centrifuged at $8000 \mathrm{~g}, 4{ }^{\circ} \mathrm{C}$ for 10 minutes. The supernatant was collected and purified using Nickel ion affinity chromatography (Qiagen) according to the manufacturer's protocol. The protein was dialyzed against phosphate buffered saline (PBS, $\mathrm{pH}$ 7.4). Protein purity and concentration were determined by SDS-PAGE and BCA protein assay kit (Takara) respectively. Western blotting was conducted using a monoclonal antibody against the poly-Histidine tag attached to the Alr protein as described previously (Liu et al., 2015).

\subsection{Enzyme assay}

Alanine racemase racemization assay was conducted in two coupled enzyme reactions, using standard racemization mixture (Wang et al., 2017). The reaction was initiated by addition of suitable concentration of SiAlr in the final reaction volume of $200 \mu 1$, incubated at $35{ }^{\circ} \mathrm{C}$ for 10 minutes, and terminated by addition of $25 \mu \mathrm{l}$ of $2 \mathrm{M} \mathrm{HCl}$ and neutralized with 25 $\mu \mathrm{l}$ of $2 \mathrm{M}$ sodium hydroxide, the reaction mixture was centrifuged at $14000 \mathrm{rpm}, 4^{\circ} \mathrm{C}$ for 10 minutes. The amount of D-alanine was measured in the second reaction containing $200 \mathrm{mM}$ Tris- $\mathrm{HCl} \mathrm{pH}:$ 8.0, $0.2 \mathrm{mg} / \mathrm{ml}$ 4-aminoantipyrine, $0.2 \mathrm{mg}$ of N-ethyl-N-(2-hydroxy-3-sulfopropyl)-3-methyl aniline, 1unit of HRP, 0.1 unit of D-Amino acid oxidase and incubated at $37{ }^{\circ} \mathrm{C}$ for 20 minutes, The absorbance was measured using a microplate reader at $550 \mathrm{~nm}$.

\subsection{Effect of temperature and $\mathrm{pH}$ on enzyme activity and stability}


Influence of temperature was determined according to standard enzyme assay by measuring initial rate of reaction at various temperatures $\left(10^{\circ} \mathrm{C}\right.$ to $\left.50^{\circ} \mathrm{C}\right)$, while the effect of $\mathrm{pH}$ was determined by measuring initial rate of reaction in Britton-Robinson buffer ( $\mathrm{pH} 2.0$ to 12.0 ) at optimum temperature. The relative residual activity was calculated with the highest activity as $100 \%$. Thermal and $\mathrm{pH}$ stability were respectively determined by incubating enzyme in a reaction mixture without substrate at $30^{\circ} \mathrm{C}, 35^{\circ} \mathrm{C}, 40^{\circ} \mathrm{C}$, and in buffers with $\mathrm{pH}$ range from 8.5 to 11.0 at $4^{\circ} \mathrm{C}$ for 2 hours, the reaction was initiated by addition of the substrate, and incubated at $35^{\circ} \mathrm{C}$ for 10 minutes. The relative activity was calculated using 0 hours sample activity as $100 \%$.

\subsection{Substrate specificity of alanine racemase}

Substrate specificity of SiAlr was determined according to standard racemization reaction mixture using 18 kinds of L-amino acid as substrates and incubated at the optimum temperature for 10 minutes.

\subsection{Effect of metal ions, reducing agents and PLP on enzyme activity}

Effect of some metal ions and chemical compounds on the activity of the enzyme were determined by incubating the enzyme with them in the reaction mixture for $30 \mathrm{~min}$, afterward, added the substrate and determined the relative residual activity according to the standard protocol (Liu et al., 2015).

Different concentrations of hydroxylamine $(0.1,1$, and $10 \mathrm{mM})$ and the enzyme were added to the reaction mixture without the substrate, dialyzed in phosphate buffered Saline for 40 min and determined its activity without the addition of PLP. The effect of Dithiothreitol (DTT) on the activity of SiAlr was determined by incubating the enzyme in different concentrations of DTT ( 1 and $3 \mathrm{mM}$ ) for 30 minutes and measured the relative activity. To confirm SiAlr is PLP dependent enzyme, the purified Alr was treated with $10 \mathrm{mM}$ hydroxylamine and dialyzed to obtain the apoenzyme. The apoenzyme was incubated in different concentrations of PLP $(0.01,0.04$ and $0.06 \mathrm{mM})$ and measured the relative activity.

\subsection{Kinetic parameters}

Alanine racemase activity was determined by measuring the amount of both enantiomers of alanine by high-performance liquid chromatography (HPLC) using a fluorescence detector 
and followed the method described earlier (Hashimoto et al., 1992). The reaction mixture containing $10 \mu \mathrm{m}$ PLP, $200 \mathrm{mM}$ carbonate buffer $\mathrm{pH} 9.5$, and various concentrations of either $\mathrm{L}$ or $\mathrm{D}$ forms of alanine, followed by enzyme addition and incubation at $35^{\circ} \mathrm{C}$ for $10 \mathrm{~min}$. The reaction was terminated by the addition of $40 \mu \mathrm{l}$ of $2 \mathrm{M} \mathrm{HCL}$ on ice for $2 \mathrm{~min}$, neutralized with $40 \mu 12 \mathrm{M} \mathrm{NaOH}$, and centrifuged at $10000 \mathrm{~g}, 4^{\circ} \mathrm{C}$ for $5 \mathrm{~min} . \mathrm{A} 40 \mu \mathrm{l}$ aliquot of the reaction was derivatized by addition of $280 \mu 1$ of $0.4 \mathrm{M}$ boric acid $\mathrm{pH} 9.0,0.1 \% \mathrm{~N}$-tert-butyloxy-carbomyl -L cysteine (Sigma) and $0.1 \%$ O-phthaldehyde. One unit of the enzyme was defined as the amount of enzyme that catalyzed the formation of $1 \mu \mathrm{mol}$ of $\mathrm{L}$ or D-alanine from either enantiomer per minute. Graph Pad Prism 6.0 was used for results analysis.

\subsection{Enzyme $\mathrm{IC}_{50}$ determination}

Inhibitory effects of homogentisic acid and hydroquinone on the activity of alanine racemase were determined as described previously (Wang et al., 2017). Fivefold dilution series (in DMSO) was prepared for the compounds, and the solutions were added to the wells of a 96-well plate to yield the final inhibitory concentrations. Each concentration was tested in triplicate. The substrate was added after incubation for $30 \mathrm{~min}$, and the fluorescence intensity was measured after the reaction. The negative control was prepared without adding chemicals to the control wells and the D-cycloserine (DCS) was used as the positive control. Percentage inhibition at each inhibitor concentration was calculated with respect to the negative control. GraphPad Prism 6.0 was used for the calculation of the concentration that causes 50\% inhibition $\left(\mathrm{IC}_{50}\right)$.

\subsection{Antimicrobial susceptibility tests}

Minimum inhibition concentrations (MIC) of hydroquinone and homogentisic acid against both Gram positive and Gram negative bacteria were determined by microdilution assay according to the guidelines of the Clinical and Laboratory Standards Institute, document M31-A3 (CLSI., 2008), as described previously (Dal Pozzo et al., 2011). An overnight culture was subculture to $\mathrm{OD}_{600}$ of 0.3 , diluted tenfold, five times. Aliquots were spread on agar plates in triplicate to determine the number of colony-forming units $(\mathrm{CFU}) / \mathrm{ml}$. Compounds were diluted in DMSO at concentrations of $200,100,80,40,20$, or $10 \mu \mathrm{g} / \mathrm{ml}$. DMSO solvent was used as a negative control of growth inhibition and DMSO alone was used as the blank control. 
All tests were performed in triplicate. The inoculum of bacteria in culture medium $\left(100 \mu \mathrm{l} ; 10^{5}\right.$

$\mathrm{CFU} ; \mathrm{OD}_{600}=0.3$ ) was added to each well-containing compounds and incubated at $30^{\circ} \mathrm{C}$ for 48

hours. MIC values were determined as the lowest concentration at which no growth was

observed upon visual inspection after incubating.

\section{Conflict of interest}

Authors have declared no conflict of interest.

\section{Acknowledgment}

This work was supported by the Natural Science Foundation of Hebei Province (C2013205103); the Outstanding Youth Foundation of Department of Education of Hebei Province (YQ2014026); the Research Fund of Hebei Normal University (L2016Z03); the State Key Laboratory of Pathogen and Biosecurity (Academy of Military Medical Science) (SKLPBS1529); and the Science and technology research project of Hebei Normal University (ZD2018070).

\section{Reference}

Anthony, K.G., Strych, U., Yeung, K.R., Shoen, C.S., Perez, O., Krause, K.L., Cynamon, M.H., Aristoff, P.A. and Koski, R.A., 2011. New classes of alanine racemase inhibitors identified by high-throughput screening show antimicrobial activity against Mycobacterium tuberculosis. PLoS One 6, e20374.

Aruety, T., Brunner, T., Ronen, Z., Gross, A., Sowers, K. and Zilberg, D., 2016. Decreasing levels of the fish pathogen Streptococcus iniae following inoculation into the sludge digester of a zero-discharge recirculating aquaculture system (RAS). Aquaculture 450, 335-341.

Awasthy, D., Bharath, S., Subbulakshmi, V. and Sharma, U., 2012. Alanine racemase mutants of Mycobacterium tuberculosis require D-alanine for growth and are defective for survival in macrophages and mice. Microbiology 158, 319-327.

Azam, M.A. and Jayaram, U., 2018. Induced fit docking, free energy calculation and molecular dynamics studies on Mycobacterium tuberculosis alanine racemase inhibitor. Molecular Simulation 44, 424-432.

Badet, B. and Walsh, C., 1985. Purification of an alanine racemase from Streptococcus faecalis and analysis of its inactivation by (1-aminoethyl) phosphonic acid enantiomers. Biochemistry 24, 1333-1341.

Batson, S., de Chiara, C., Majce, V., Lloyd, A.J., Gobec, S., Rea, D., Fülöp, V., Thoroughgood, C.W., Simmons, K.J. and Dowson, C.G., 2017. Inhibition of D-Ala: D-Ala ligase through a phosphorylated form of the antibiotic D-cycloserine. Nature communications $8,1939$. 
Chacon, O., Feng, Z., Harris, N.B., Cáceres, N.E., Adams, L.G. and Barletta, R.G., 2002. Mycobacterium smegmatis D-alanine racemase mutants are not dependent on D-alanine for growth. Antimicrobial agents and chemotherapy 46, 47-54.

Clinical Laboratory Standards Institute. Antimicrobial disk and dilution susceptibility tests for bacteria isolated from animals. Approved standard, 3rd ed. Wayne: CLSI; 2008. CLSI Document M31-A3

Couñago, R.M., Davlieva, M., Strych, U., Hill, R.E. and Krause, K.L., 2009. Biochemical and structural characterization of alanine racemase from Bacillus anthracis (Ames). BMC structural biology $9,53$.

Dal Pozzo, M., Viégas, J., Santurio, D.F., Rossatto, L., Soares, I.H., Alves, S.H. and Costa, M.M.d., 2011. Atividade antimicrobiana de óleos essenciais de condimentos frente a Staphylococcus spp. Isolados de mastite caprina. Ciência Rural 11, 54-56.

Duque, E., Daddaoua, A., Cordero, B.F., De la Torre, J., Antonia Molina-Henares, M. and Ramos, J.L., 2017. Identification and elucidation of in vivo function of two alanine racemases from Pseudomonas putida KT2440. Environmental microbiology reports 9, 581-588.

Francois, J.A. and Kappock, T.J., 2007. Alanine racemase from the acidophile Acetobacter aceti. Protein expression and purification 51, 39-48.

Guo, S., Mo, Z., Wang, Z., Xu, J., Li, Y., Dan, X. and Li, A., 2018. Isolation and pathogenicity of Streptococcus iniae in offshore cage-cultured Trachinotus ovatus in China. Aquaculture 492, 247-252.

Hashimoto, A., Nishikawa, T., Oka, T., Takahashi, K. and Hayashi, T., 1992. Determination of free amino acid enantiomers in rat brain and serum by high-performance liquid chromatography after derivatization with N-tert.-butyloxycarbonyl-L-cysteine and o-phthaldialdehyde. Journal of Chromatography B: Biomedical Sciences and Applications 582, 41-48.

Higashi, T., 1958. Two types of hydroquinone oxidase of Pseudomonas aeruginosa. The Journal of Biochemistry 45, 785-793.

Hunter, R.C. and Newman, D.K., 2010. A putative ABC transporter, hatABCDE, is among molecular determinants of pyomelanin production in Pseudomonas aeruginosa. Journal of bacteriology 192, 5962-5971.

Im, H., Sharpe, M.L., Strych, U., Davlieva, M. and Krause, K.L., 2011. The crystal structure of alanine racemase from Streptococcus pneumoniae, a target for structure-based drug design. BMC microbiology 11, 116.

Ju, J., Xu, S., Wen, J., Li, G., Ohnishi, K., Xue, Y. and Ma, Y., 2009. Characterization of endogenous pyridoxal 5'-phosphate-dependent alanine racemase from Bacillus pseudofirmus OF4. Journal of bioscience and bioengineering 107, 225-229.

Kawakami, R., Ohshida, T., Sakuraba, H. and Ohshima, T., 2018. A Novel PLP-Dependent Alanine/Serine Racemase From the Hyperthermophilic Archaeon Pyrococcus horikoshii OT-3. Frontiers in microbiology 9, 1481.

Kim, M.G., SBYCH, U., Krause, K., Benedik, M. and Kohn, H., 2003a. Evaluation of amino-substituted heterocyclic derivatives as alanine racemase inhibitors. Medicinal chemistry research 12, 130-138. 
Kim, M.G., Strych, U., Krause, K., Benedik, M. and Kohn, H., 2003b. N (2)-Substituted D, L-Cycloserine Derivatives. The Journal of antibiotics 56, 160-168.

Lee, Y., Mootien, S., Shoen, C., Destefano, M., Cirillo, P., Asojo, O.A., Yeung, K.R., Ledizet, M., Cynamon, M.H. and Aristoff, P.A., 2013. Inhibition of mycobacterial alanine racemase activity and growth by thiadiazolidinones. Biochemical pharmacology 86 , 222-230.

Liu, D., Liu, X., Zhang, L., Jiao, H., Ju, J. and Zhao, B., 2015. Biochemical characteristics of an alanine racemase from Aeromonas hydrophil HBNUAh01. Microbiology 84, 202-209.

Liu, D., Zhang, T., Wang, Y., Muhammad, M., Xue, W., Ju, J. and Zhao, B., 2019. Knockout of alanine racemase gene attenuates the pathogenicity of Aeromonas hydrophila. BMC microbiology 19, 72.

Liu, S., Wei, Y., Zhou, X., Zhang, K., Peng, X., Ren, B., Chen, V., Cheng, L. and Li, M., 2018. Function of alanine racemase in the physiological activity and cariogenicity of Streptococcus mutans. Scientific reports 8, 5984.

Muhammad, M., Zhang, T., Gong, S., Bai, J., Ju, J., Zhao, B., Liu, D., 2019. Streptococcus iniae: A Growing Threat and Causative Agent of Disease Outbreak in Farmed Chinese Sturgeon (Acipenser sinensis). Pakistan Journal of Zoology Accepted manuscript.

Nachbauer, C.A., James, J.H., Edwards, L.L., Ghory, M.J. and Fischer, J.E., 1984. Infusion of branched chain-enriched amino acid solutions in sepsis. The American journal of surgery $147,743-752$.

Nakatani, Y., Opel-Reading, H.K., Merker, M., Machado, D., Andres, S., Kumar, S.S., Moradigaravand, D., Coll, F., Perdigão, J. and Portugal, I., 2017. Role of alanine racemase mutations in Mycobacterium tuberculosis D-cycloserine resistance. Antimicrobial agents and chemotherapy 61, e01575-17.

Palumbo, E., Favier, C.F., Deghorain, M., Cocconcelli, P.S., Grangette, C., Mercenier, A., Vaughan, E.E. and Hols, P., 2004. Knockout of the alanine racemase gene in Lactobacillus plantarum results in septation defects and cell wall perforation. FEMS microbiology letters 233, 131-138.

Patrick, W.M., Weisner, J. and Blackburn, J.M., 2002. Site-directed mutagenesis of Tyr354 in Geobacillus stearothermophilus alanine racemase identifies a role in controlling substrate specificity and a possible role in the evolution of antibiotic resistance. Chembiochem 3, 789-792.

Qiu, W., Zheng, X., Wei, Y., Zhou, X., Zhang, K., Wang, S., Cheng, L., Li, Y., Ren, B. and Xu, X., 2016. d-Alanine metabolism is essential for growth and biofilm formation of Streptococcus mutans. Molecular oral microbiology 31, 435-444.

Ray, S., Das, S., Panda, P.K. and Suar, M., 2018. Identification of a new alanine racemase in Salmonella Enteritidis and its contribution to pathogenesis. Gut pathogens 10, 30.

Saavedra, M.J., Guedes-Novais, S., Alves, A., Rema, P., Tacão, M., Correia, A. and Martínez-Murcia, A., 2004. Resistance to $\beta$-lactam antibiotics in Aeromonas hydrophila isolated from rainbow trout (Onchorhynchus mykiss). International Microbiology 7, 207-211. 
Scaletti, E.R., Luckner, S.R. and Krause, K.L., 2012. Structural features and kinetic characterization of alanine racemase from Staphylococcus aureus (Mu50). Acta Crystallographica Section D: Biological Crystallography 68, 82-92.

Seow, T.K., Inagaki, K., Tamura, T., Soda, K. and Tanaka, H., 1998. Alanine racemase from an acidophile, Acidiphilium organovorum: purification and characterization. Bioscience, biotechnology, and biochemistry 62, 242-247.

Shrestha, R., Lockless, S.W. and Sorg, J.A., 2017. A Clostridium difficile alanine racemase affects spore germination and accommodates serine as a substrate. Journal of Biological Chemistry 292, 10735-10742.

Soda, K. and Tanizawa, K., 1990. Thermostable Alanine Racemase. Annals of the New York Academy of Sciences 585, 386-393.

Strych, U., Davlieva, M., Longtin, J.P., Murphy, E.L., Im, H., Benedik, M.J. and Krause, K.L., 2007. Purification and preliminary crystallization of alanine racemase from Streptococcus pneumoniae. BMC microbiology 7, 40.

Tassoni, R., van der Aart, L.T., Ubbink, M., Van Wezel, G.P. and Pannu, N.S., 2017. Structural and functional characterization of the alanine racemase from Streptomyces coelicolor A3 (2). Biochemical and biophysical research communications 483, 122-128.

Tavares, G.C., de Queiroz, G.A., Assis, G.B.N., Leibowitz, M.P., Teixeira, J.P., Figueiredo, H.C.P. and Leal, C.A.G., 2018. Disease outbreaks in farmed Amazon catfish (Leiarius marmoratus $x$ Pseudoplatystoma corruscans) caused by Streptococcus agalactiae, $S$. iniae, and S. dysgalactiae. Aquaculture.

Teulé, F., Cooper, A.R., Furin, W.A., Bittencourt, D., Rech, E.L., Brooks, A. and Lewis, R.V., 2009. A protocol for the production of recombinant spider silk-like proteins for artificial fiber spinning. Nature protocols $4,341$.

Toney, M.D., 2005. Reaction specificity in pyridoxal phosphate enzymes. Archives of biochemistry and biophysics 433, 279-287.

Wang, Y., Yang, C., Xue, W., Zhang, T., Liu, X., Ju, J., Zhao, B. and Liu, D., 2017. Selection and characterization of alanine racemase inhibitors against Aeromonas hydrophila. BMC microbiology 17, 122.

Wei, Y., Qiu, W., Zhou, X.-D., Zheng, X., Zhang, K.-K., Wang, S.-D., Li, Y.-Q., Cheng, L., Li, J.-Y. and Xu, X., 2016. Alanine racemase is essential for the growth and interspecies competitiveness of Streptococcus mutans. International journal of oral science 8, 231.

Yokoigawa, K., Kawai, H., Endo, K., Lim, Y.H., Esaki, N. and Soda, K., 1993. Thermolabile alanine racemase from a psychrotroph, Pseudomonas fluorescens: purification and properties. Bioscience, biotechnology, and biochemistry 57, 93-97. 


\section{Figures}

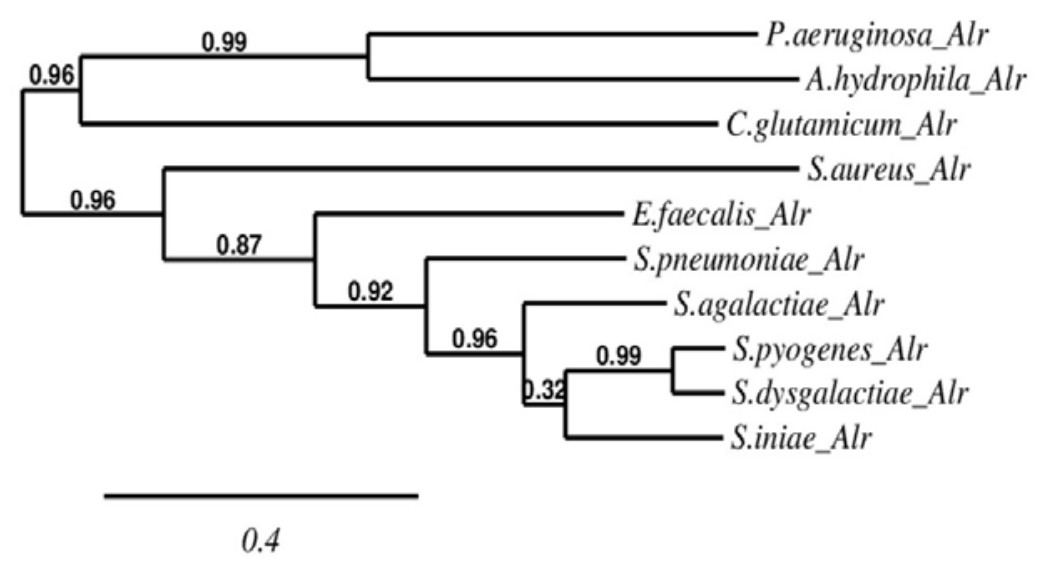

Fig. 1. Phylogenetic relationships of SiAlr and sequences from 10 other species. The tree was constructed using Neighbor end-joining. Maximum likelihood tree based on complete coding sequences deposited in GenBank. The evolutionary distances were computed using the p-distance method while the scale bar indicates 0.4 amino acid substitutions per site. 


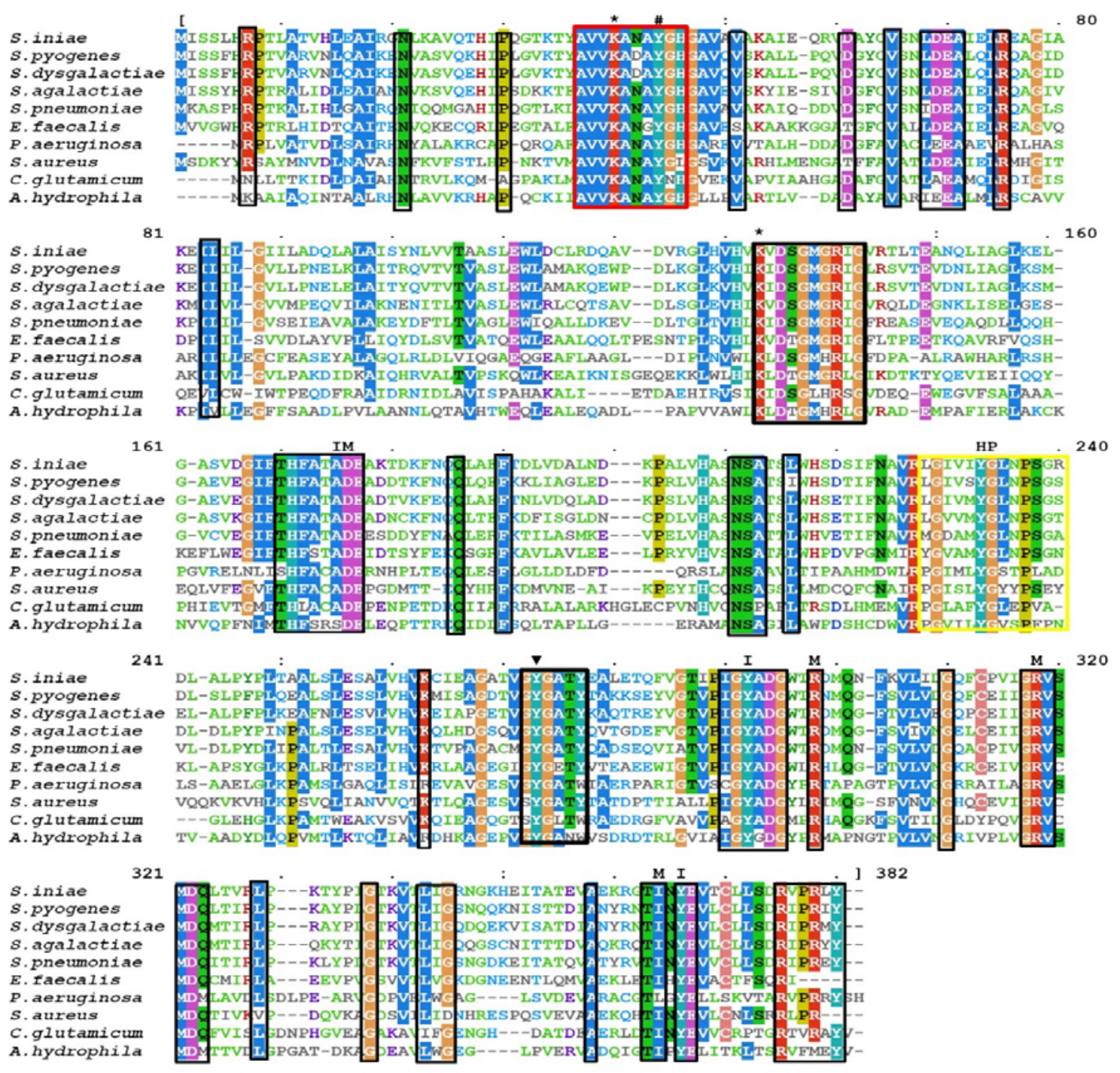

Fig. 2. Structure-based sequence alignment of alanine racemases sequences. The amino acid sequence of Alr from S. iniae was aligned with alanine racemases sequences of $S$. uberis CAIM 1894, S. agalactiae 2603V/R, E. feacalis D32, B. anthracis H9401, S. aureus ABFQT, C. glutamicum ATCC 13032, A. hydrophyla ATCC 7966, S. pneumoniae MDRSPN001, and E.coli CVM N33720P. The red box enclosed the conserved PLP-binding sites; Lys40 (*), Tyr44 (\#). The catalytic Tyr residue was indicated by (+). Strictly conserved residues were enclosed in the black boxes, while the hydrophobic patch (HP) in the yellow box. Residues of 
the active site entryway are marked with either I (inner layer) or M (middle layer). Highly conserved residues were indicated by the box and strictly conserved with $\left(^{*}\right)$.

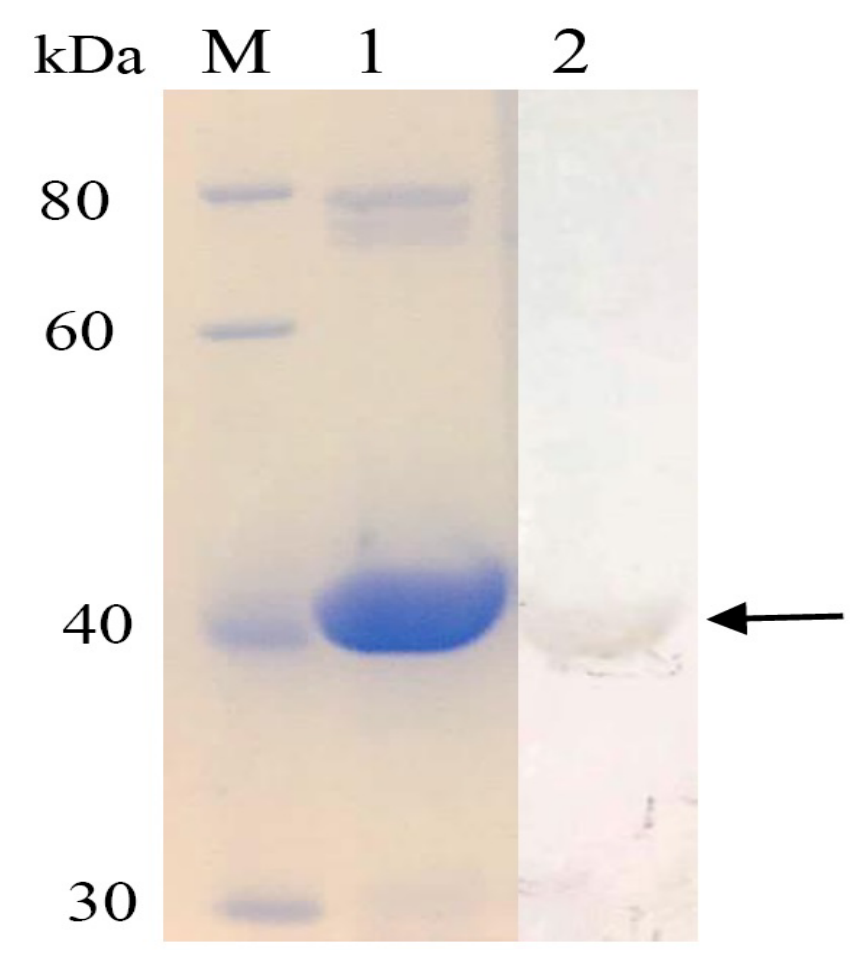

Fig. 3. Purification of $S$. iniae alanine racemase. The enzyme was purified using Nickel ion affinity chromatography, analyzed by SDS-PAGE and western blotting. M: molecular weight standards; Lane 1: Protein marker, Lane 2; $40 \mathrm{kDa}$ SiAlr. Lane 2: Western blotting analysis of the purified protein. 

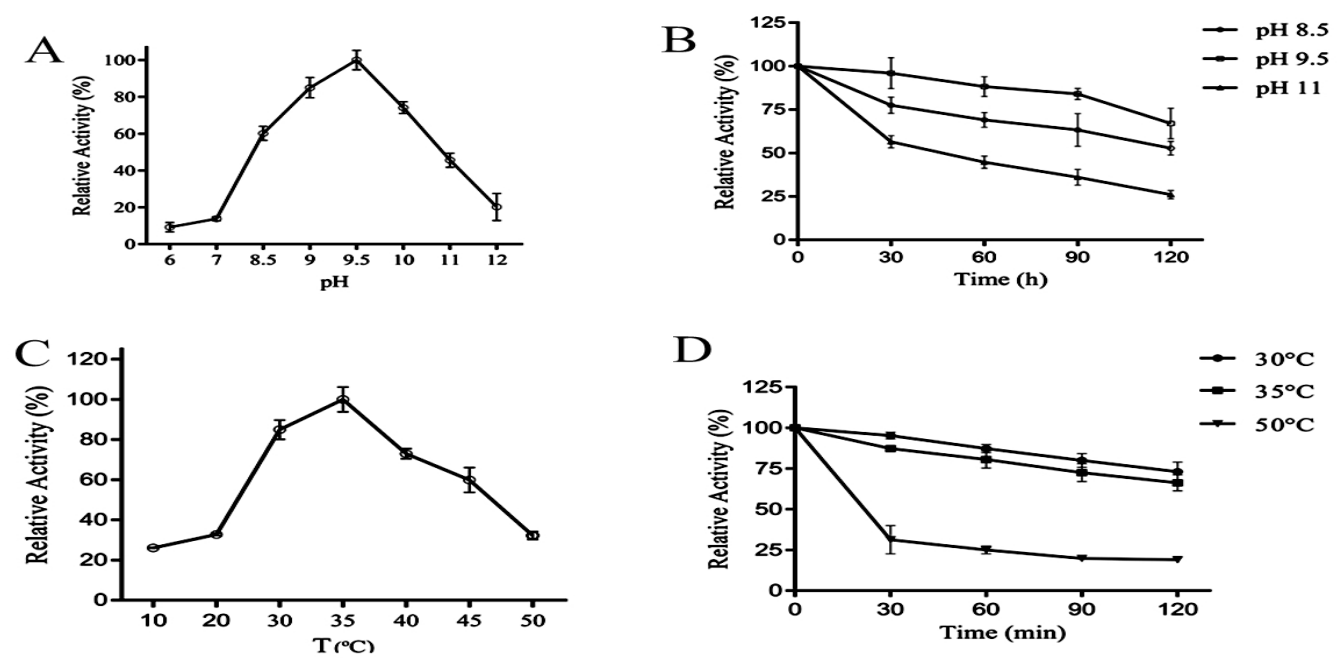

Fig. 4. Effect of $\mathrm{pH}$ and Temperature on the activity of SiAlr. (A) Optimal pH; (B) pH stability; (C) Optimal temperature; (D) Thermal stability.

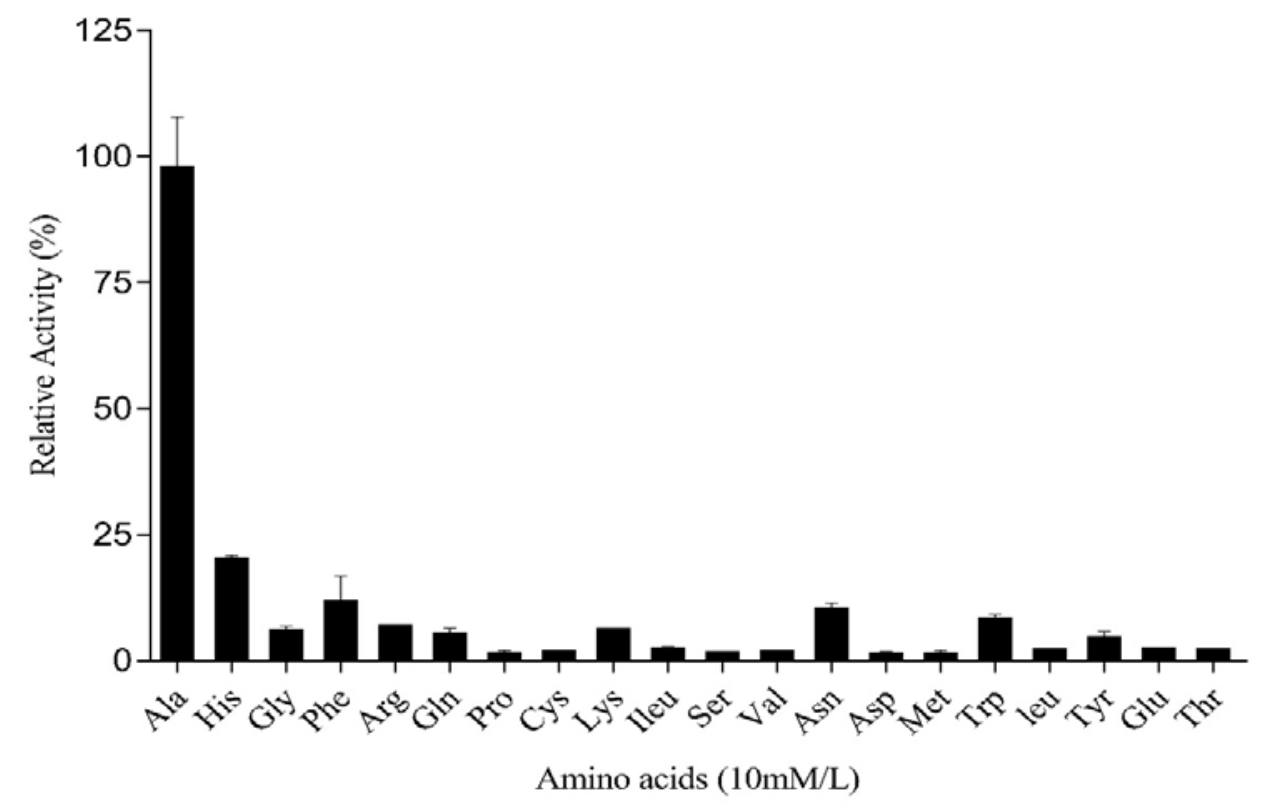

Fig. 5. Effect of metals on SiAlr activity. The metal ions were at a concentration of $10 \mathrm{mM} / 1$.

The data were presented as mean \pm SD from 3 independent determinations. 


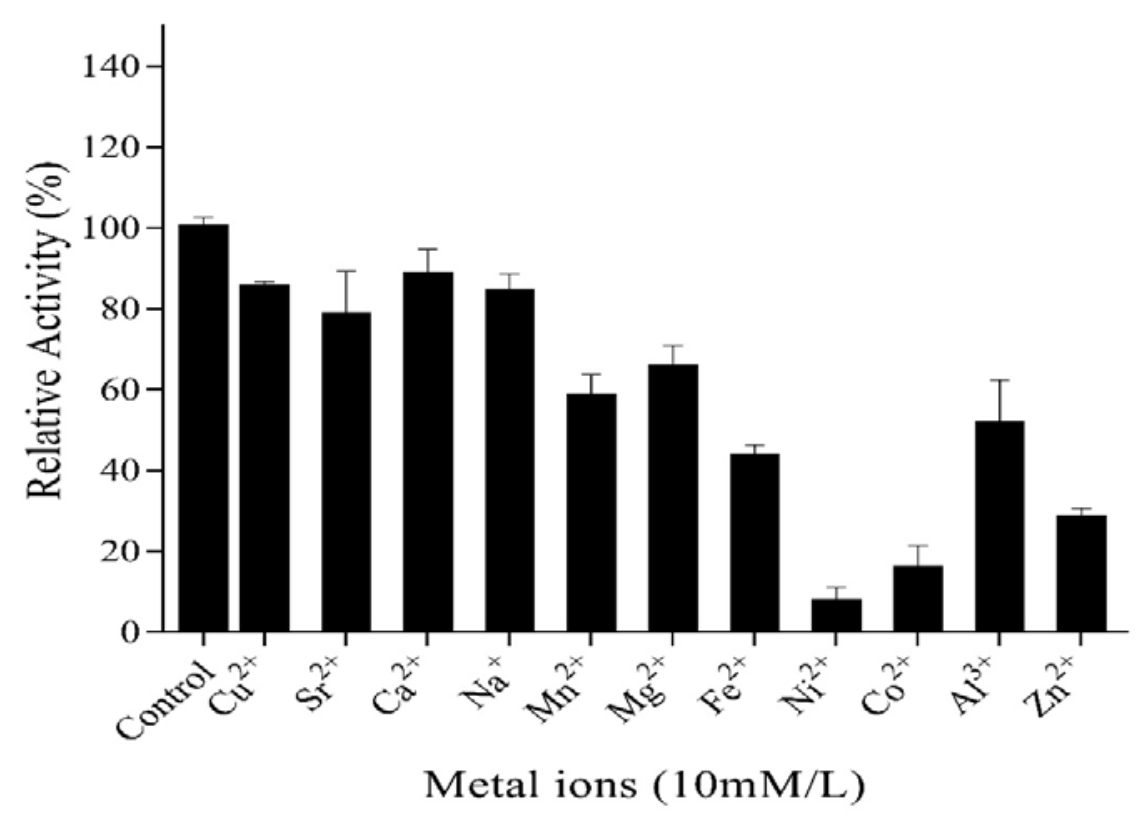

Fig. 6. The substrate specificity of SiAlr. The relative activity of SiAlr for various L-Amino acids was determined at optimum $\mathrm{pH}$ and temperature. The data were presented as mean \pm SD from 3 independent enzyme assays.
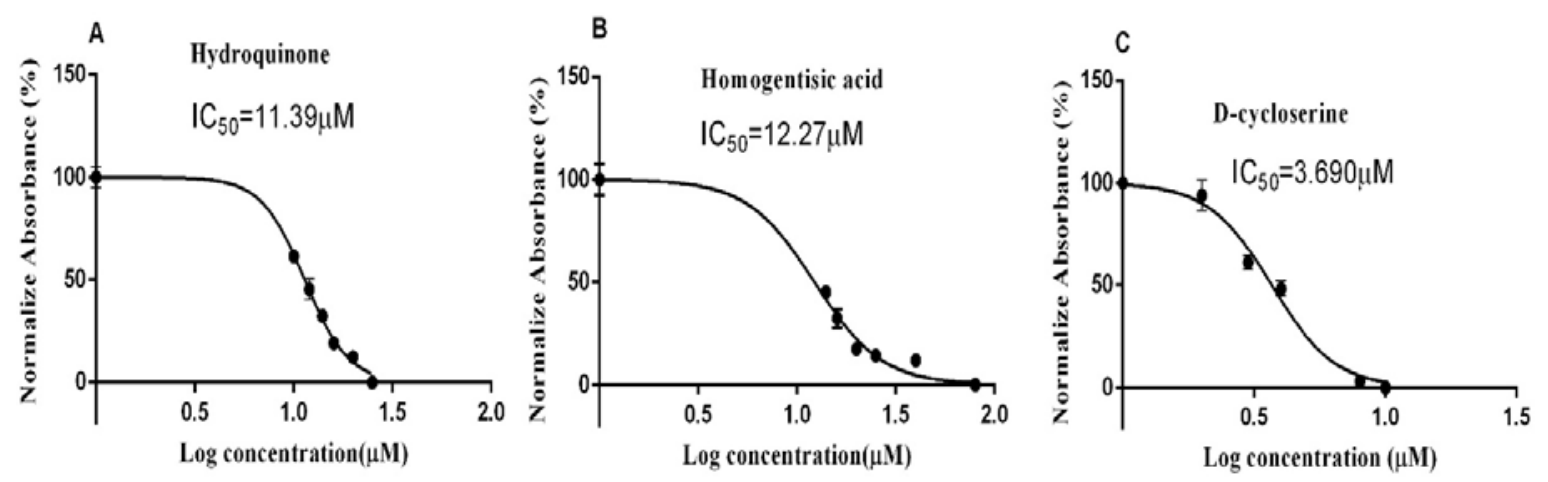

Fig. 7. $\mathrm{IC}_{50}$ of the $S$. iniae alanine racemase inhibitor. A: $\mathrm{IC}_{50}$ of Hydroquinone was $11.39 \mu \mathrm{M}$;

$\mathrm{B}$ : $\mathrm{IC}_{50}$ of homogentisic acid was $12.27 \mu \mathrm{M}$; C: $\mathrm{IC}_{50}$ of D-cycloserine was $3.69 \mu \mathrm{M}$. The data shown are the means from three independent experiments. 
Table 1 Strains and plasmids used in this study.

\begin{tabular}{|c|c|c|}
\hline Strains/Plasmids & Description & Source \\
\hline \multicolumn{3}{|l|}{ Strains } \\
\hline S. iniae HNM-1 & isolated from infected Acipenser sinensis & This study \\
\hline E. coli $\mathrm{DH} 5 \alpha$ & used for cloning and propagation of plasmids & Novagen \\
\hline E. coli BL21(DE3) & used for protein expression & Invitrogen \\
\hline Salmonella & & This study \\
\hline Staphylococcus aureus & & This study \\
\hline Acinetobacter baumannii & & This study \\
\hline Pseudomonas aeruginosa & & This study \\
\hline \multicolumn{3}{|l|}{ Plasmids } \\
\hline pMD19-T & $\begin{array}{l}\text { carries ampR gene; used for cloning PCR } \\
\text { product with A at 3' ends }\end{array}$ & Takara \\
\hline pET 22b (+) & $\begin{array}{l}\text { carries ampR gene; used for expressing } S \text {. iniae } \\
\text { Alanine racemase }\end{array}$ & Novagen \\
\hline
\end{tabular}


Table 2: Effect of Hydroxylamine, DTT and PLP on SiAlr Activity.

\begin{tabular}{lll}
\hline Chemical & Concentration, mM & Relative activity, $\%$ \\
\hline None & 0.1 & $100(0.7)$ \\
Hydroxylamine & 1 & $21(1.2)$ \\
& 10 & $11(0.8)$ \\
DTT & 1 & $9(1.4)$ \\
& 3 & $27(3.1)$ \\
PLP & 0.01 & $2(0.8)$ \\
& 0.04 & $56(2.4)$ \\
& 0.06 & $83(1.5)$ \\
\hline
\end{tabular}

The data were presented as mean (SD) from 3 independent enzyme reactions. 
Table 3. Kinetic parameters of SiAlr. The parameters were determined using HPLC and analyzed with Graph prism 6.0. The data were presented as mean \pm SD from 3 independent

\begin{tabular}{|c|c|c|c|c|c|c|}
\hline \multirow[b]{2}{*}{ Enzyme } & \multicolumn{2}{|c|}{ L to D-alanine } & \multicolumn{2}{|c|}{ D to L-alanine } & \multirow{2}{*}{$\mathrm{K}_{\mathrm{eq}}(\mathrm{L} / \mathrm{D})$} & \multirow{3}{*}{ assays. } \\
\hline & $\mathrm{K}_{\mathrm{m}}(\mathrm{mM})$ & $\mathrm{V}_{\max }($ units/mg) & $\mathrm{K}_{\mathrm{m}}(\mathrm{mM})$ & $\mathrm{V}_{\max }($ units/mg) & & \\
\hline SiAlr & 33.11 & 2426 & 14.36 & 963.6 & -1.09 & \\
\hline
\end{tabular}


Table 4. The results of antimicrobial activity of homogentisic acid and hydroquinone inhibitors against numerous isolates of gram-positive and gram-negative bacteria.

\begin{tabular}{lll}
\hline Organism & \multicolumn{2}{c}{${ }^{\mathrm{a}} \mathrm{MIC}(\mu \mathrm{g} / \mathrm{ml})$} \\
\hline S. iniae HNM-1 & $25(2.3)$ & $200(5.6)$ \\
Escherichia coli $\mathrm{DH} 5 \alpha$ & $130(7.9)$ & $210(8.4)$ \\
Salmonella & $150(8.7)$ & $180(11.4)$ \\
Staphylococcus aureus & $210(13.7)$ & $250(14.1)$ \\
Acinetobacter baumannii & $180(11.5)$ & $210(12.3)$ \\
Pseudomonas aeruginosa & 0 & 0 \\
\hline
\end{tabular}

${ }^{\mathrm{a}} \mathrm{MIC}$, average values with standard deviations. 